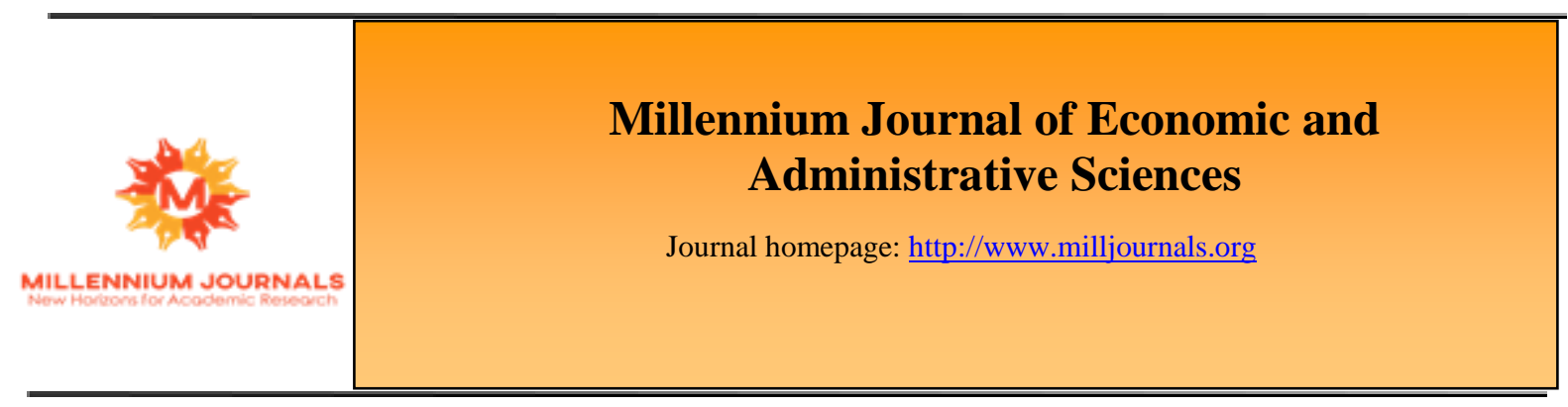

\title{
إدارة مخاطر الأمن السييراني في البنوك الأردنية
}

\author{
الاكتور احمد محمود الزيود

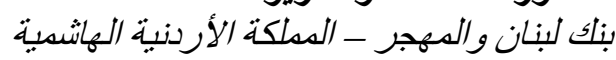 \\ https://doi.org/10.47340/mjeas.v1i1.2.2020
}

\begin{abstract}
الملخص:

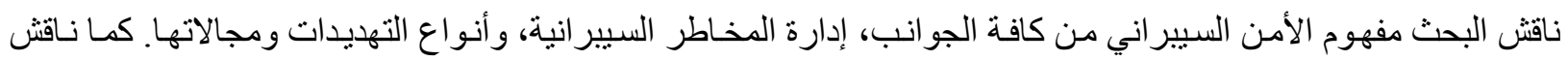

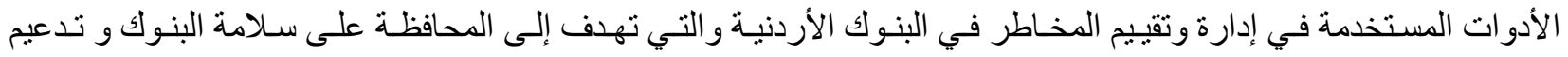

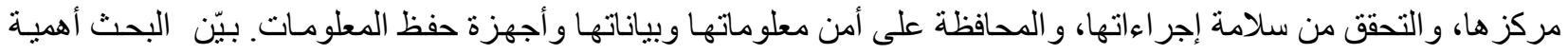

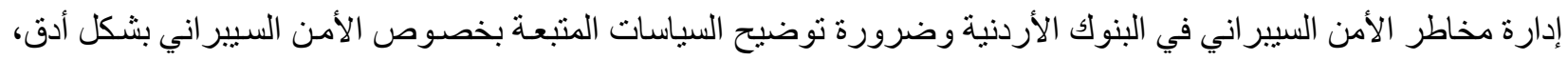

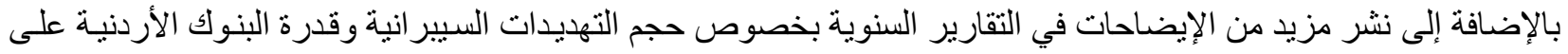

الكلمات المفتاحية: الأمن السييراني، البنوك الأردنية، أدوات إدارة وتقييم المخاطر
\end{abstract}

\section{Managing Cybersecurity Risks in Jordanian Banks}

Dr. Ahmed Mahmoud Al-Zyoud

BLOM Bank - The Hashemite Kingdom of Jordan

\section{ABSTRACT}

The research discussed the concept of cyber security in all aspects, managing cyber risks, and the types and fields of threats. The research also discussed the tools used in managing and assessing risks in Jordanian banks, which aim to maintain the safety of banks and strengthen their position, verify the integrity of their procedures, and maintain the security of their information, data, and information-storage devices. The research explored the importance of managing cyber security risks in Jordanian banks and the need to clarify the policies followed regarding cyber security more precisely, in addition to publishing more clarifications in the annual reports regarding the size of cyber threats and the ability of Jordanian banks to address them.

Keywords: cyber security, Jordanian banks, risk assessment, management tools 


\section{مشكلة الاراسة:}

تعالج الدر اسة إدارة مخاطر الأمن السيبر اني في البنوك الأردنية.

هدف الارسةة:

بيـان أهميـة الأمسن السييراني في البنوك الأردنيـة من خـلال دراسـة إدارة المخـاطر التي تعترض أمن المعلومـات في البنوك و الأدوات المستخدمة في إدارة وتقييم المخاطر.

أهمية الدراسة:

الار اسـة تعـالج موضوع مهم وحاسـم للبنوك مـن خـلال التعرف على أدوات إدارة وتقييم مخـاطر الأمن السيبراني في البنوك الأردنية.

منهجية الدراسة:

سيقوم الباحث بإتباع المنهج الوصفي و التحليلي، لوصف أدوات إدارة وتقييم مخـاطر الأمن السيير اني في البنوك الأردنية، وبيـان

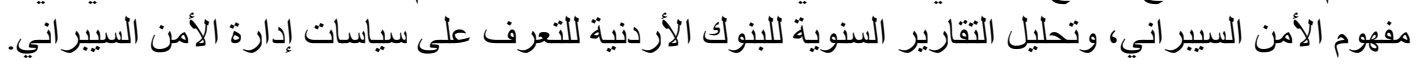

مخطط الار اسة:

تم تقسيم الدر اسة إلي مبحثين، المبحث الأول يتناول مفهوم الأمن السيير اني بشكل عام، وفي الثناني نستعرض أدوات إدارة وتقييم مخاطر الأمن السيبر اني في البنوك الأردنية

المبحث الأول: مفهوم الأمن السيبر اني

مقدمة:

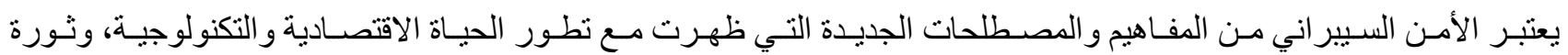

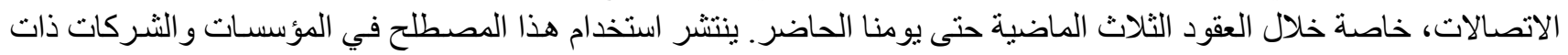

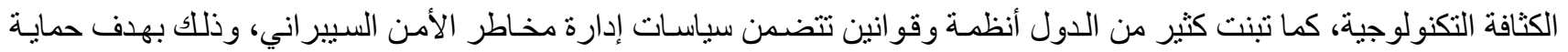

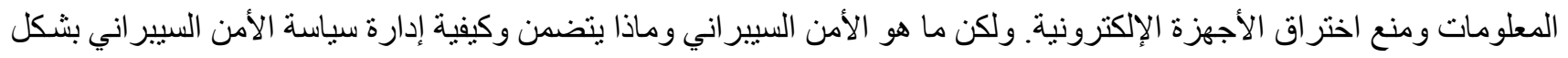
عام وفي البنوك بشكل خاص.

\section{مفهوم الأمن السيبرانى:}

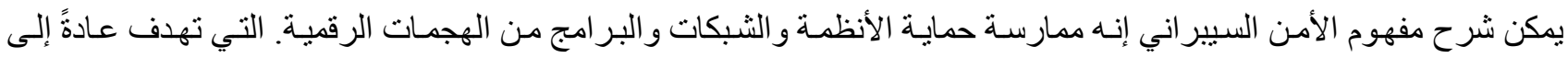

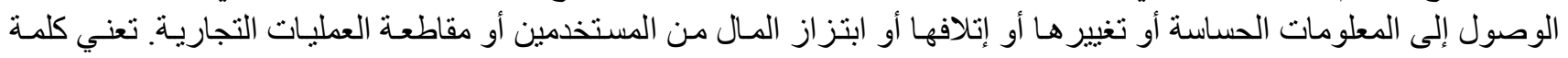

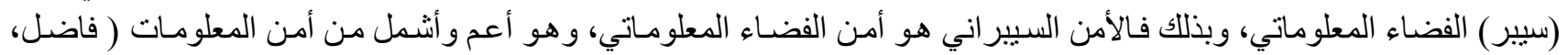

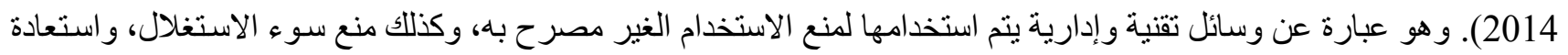

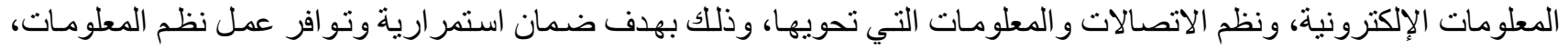

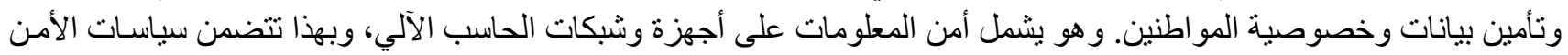

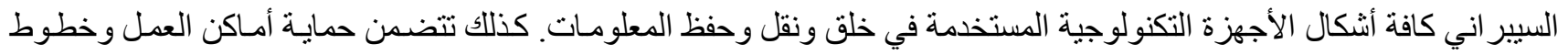

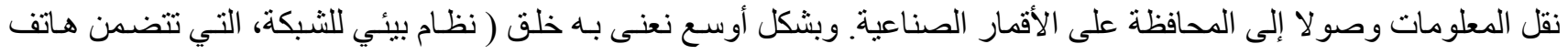
و أسلاك وخو ادم) (الخملي، 2013).

ويعرف الأمن السيبراني بإنه (مجموعة الأنشطة والتدابير سواء التقنية أو غير التقنبة، التي تهدف إلى حمايـة بيئة الكهرباء الحيوية و البيانات التي يحتوي عليها ومن كل تهديد محتمل) ( الهيئة الوطنية للامن السبر انية).

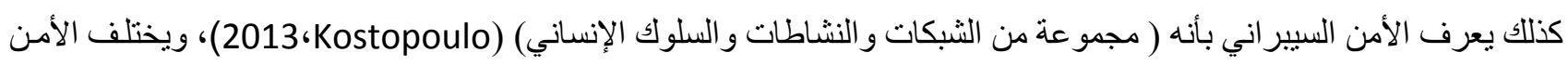

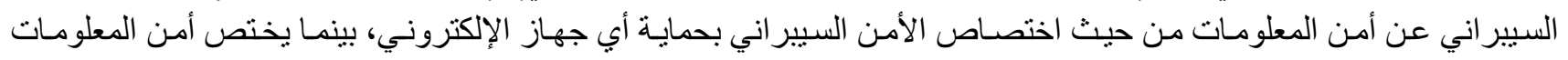


بحماية أي معلومة موجودة على الورق أم الكترونيا". كذللك فإن الأمن السيبر اني يهتم بأمن الثروة الرقمية و الثقافية للناس وللمنظمات

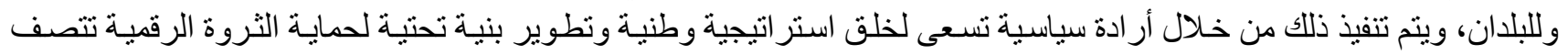
بالتماسك و الفعالية و الموضو عية وقابلية الإدارة (الحجو، 2011). إدارة مخاطر الأمن السيبيرانى :

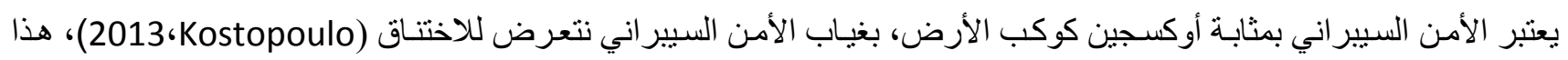

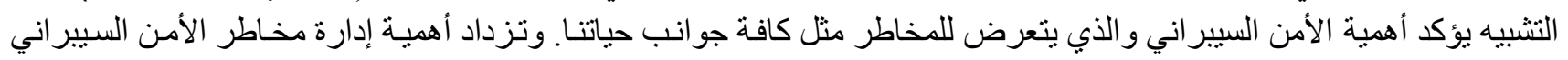

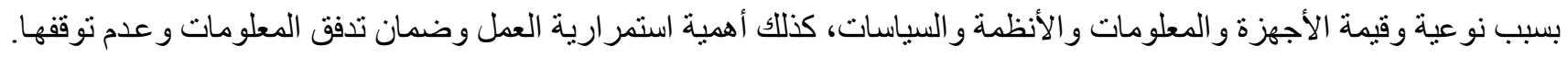

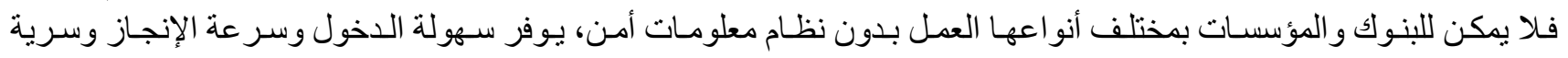

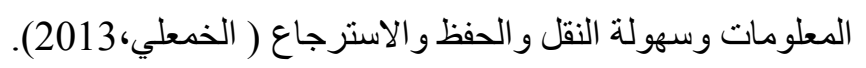
أنواع التهويدات السييرانية تشمل التهديدات ثلاث أنواع من التهديدات السيبر انية التي يمكنها مهاجمة الأجهزة و الثبكات؛ وهي الهجمات على السرية، النزاهة، و التو افر (العمر اوي، 2016).

\section{Confidentiality) الهجمات على السرية}

تشمل سرقة معلومـات التعريف الثخصية، والحسـابات المصرفية، أو معلومـات بطاقة الائتمان، حيث يقوم العديد من المهاجمين

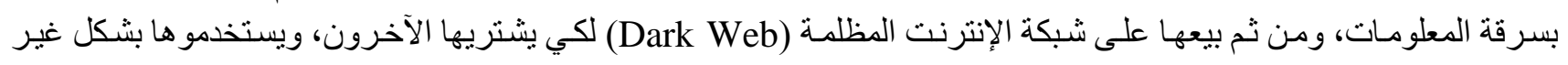
شرعي.

\section{الهجمات على النزاهة(Integrity)}

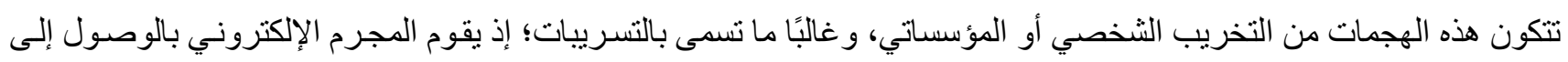

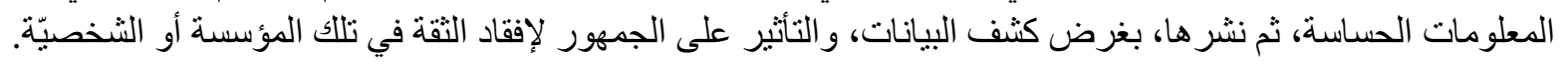

\section{(Availability) •}

الهدف منها هو منع المستخدمين من الوصول إلى بياناتهم الخاصة إلى أن يدفعو ارسومًا ماليّة، أو فدية معيّنة. مجالات التهايدات الإكترونية

$$
\text { هناك العديد من المجالات لحدوث التهديدات الإلكترونية وهي (حازم، 2010): }
$$

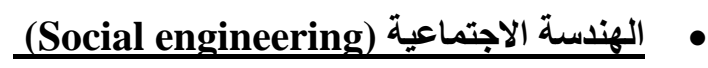

هي نوع من أنواع الهجوم على السرية، وتنطوي على عملية التلاعب النفسي في أداء الأعمال، أو دفع الضحية للتخلي عن معلومات مهمّة.

\section{التهديديات المستمرة المثقدّمة (Advanced Persistent Threats)}

تُعرف اختصارًا ب APTs ، و هي نوع من أنواع الهجوم على النز اهلة، يتسلل فيها مستخدم غير مصر ح بـه إلى شبكة غير مكتشفة

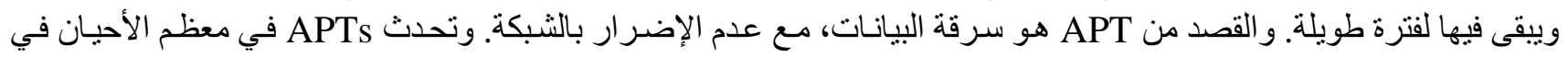

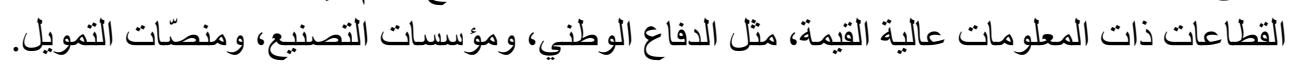

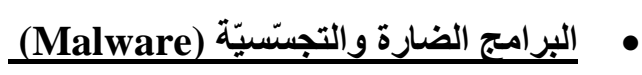

هي نوع من أنواع الهجوم على التو افر. تثشير إلى برنـامج مصمع لانتز اع الوصول، أو إتلاف جهاز الكمبيوتر دون معرفة المالك.

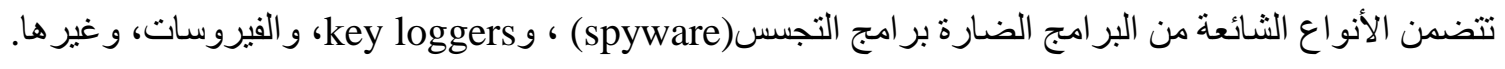




\section{أهمية الأمن السيبراني}

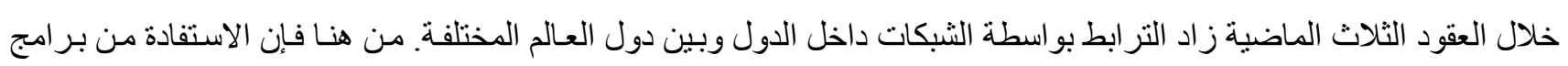

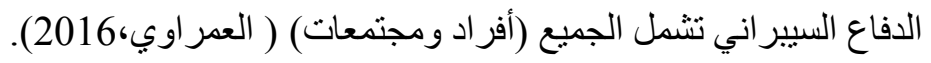
مستوى الأفراد : يتعرض الأفر اد إلى عدة أنواع من هجمـات الأمن السيبر اني مثل سـرقة الهويـة أو محساو لات الابتزاز أو فقدان البيانات المهمة مثل الصور لتعرضور الإئلي. مستوى المجتمع: تتعدد خدمات البنية التحتية الحيوية التي يعتمد أفر اد المجتمع عليها، مثنل محطات الطاقة و المستشفيات وشركات

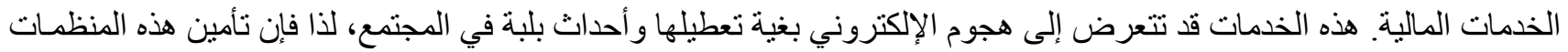
و غير ها أمر ضروري المالة، للحفاظ على عمل مجتمعنا بطريقة آمنة وطبيعية. شمولية مصطلح الأمن السيبراني يشمل مصطلح الأمن السيبراني عدة قطاعات، مثل من قطاع الأعمال، وقطاع الحوسبة المتنقلة، وبالعموم تقسم إلى (الثمر اني،

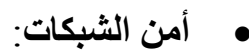

هو ممارسة تأمين شبكة الكمبيوتر من العناصر المتطفلة والانتهازية، سو اء المهاجمين المستهدفين، أو البر امج الضارة. • مان التطبيقات:

بركز على الحفاظ على البرامج والأجهزة خالية من التهديدات، إذ يمكن أن يوفر التطبيق المخترق الوصول إلى البيانات المصممة

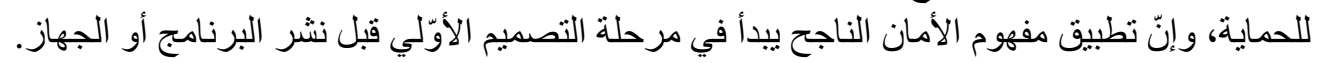

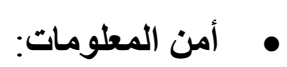

يحمي سلامة وخصوصية البيانات، سواء في مرحلة التخزين أو التناقل.

$$
\text { • الأمن التشغيلي: }
$$

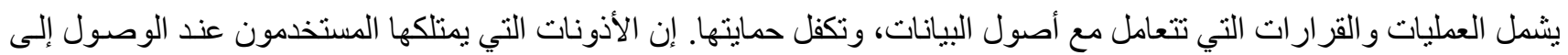

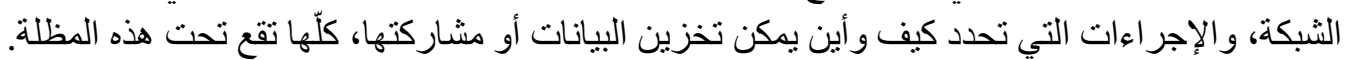

\section{• الاسترداد بعد الكوارث واستمرارية الأعمال:}

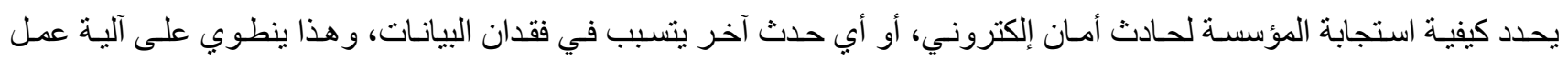

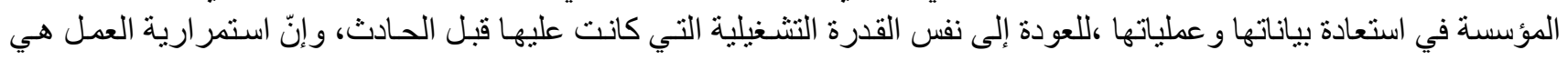

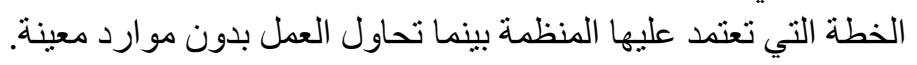

\section{الأهف من إدارة الأمن السيبراني}

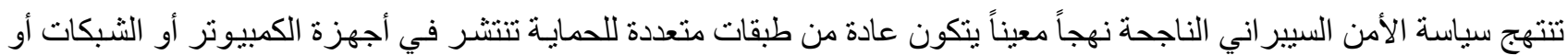

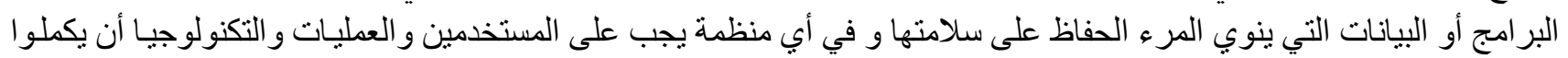

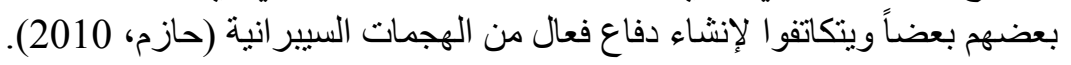

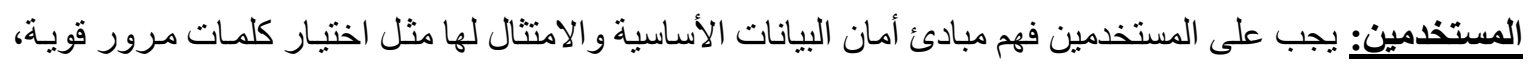

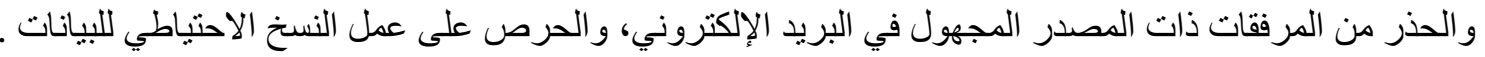

التكنولوجيا : تعد التكنولوجيا ضرورة ملحة لمنح المنظمات والأفراد أدوات الحماية اللازمة من الهجمات السيبرانية .

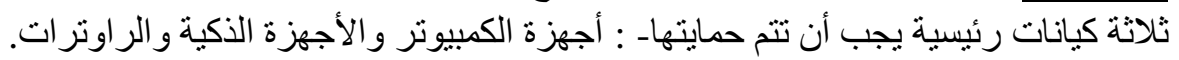




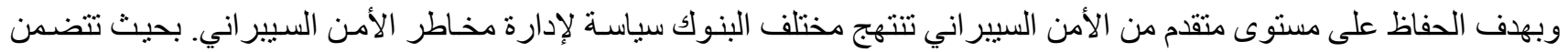

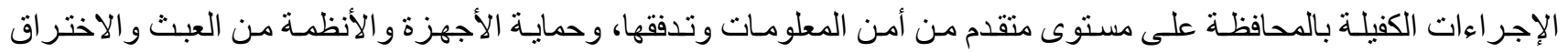

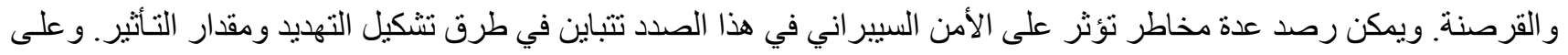

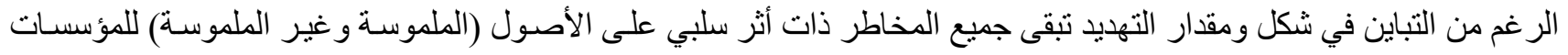

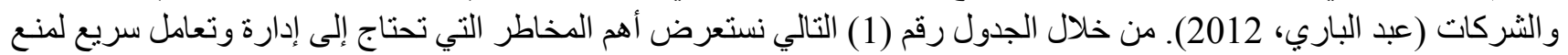

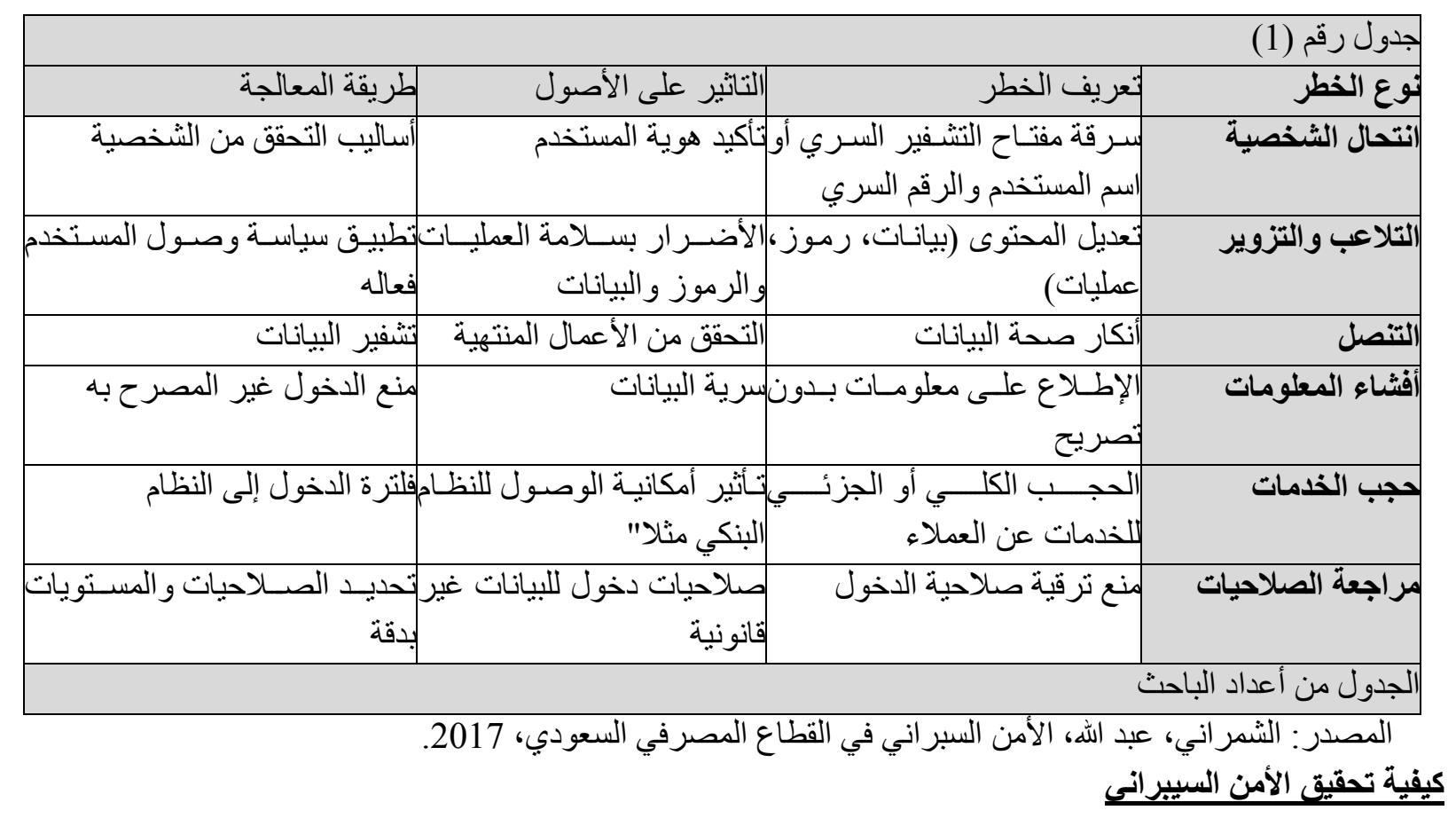

هنالك عدة أساليب وطرق لتحقيق الأمان و السلامة السيبر انية (الجلاب، 2014):

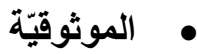

استخدم فقط المو اقع الموثوق بها عند تقديم معلوماتكاك الثخصية، و القاعدة الأساسية الفضلى هنا هي التحقق من عنوان أنسان

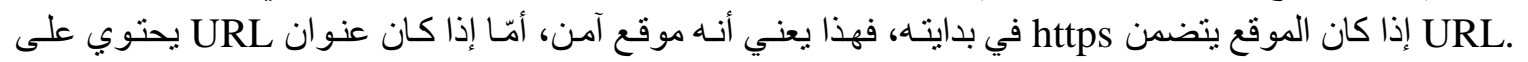
hبدون sttp فتجنب إدخال أبيّ معلومات حساسة مثل بيانات بطاقة الائتمان، أو رقم التأمين الاجتماعي. أنيا.

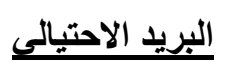

لا تفتح مرفقات البريد الإلكتروني أو تتقر فوق رو ابط الرسائل من المصادر غير المعروفة، إذ إنّ إحدى الطرق الأكثر

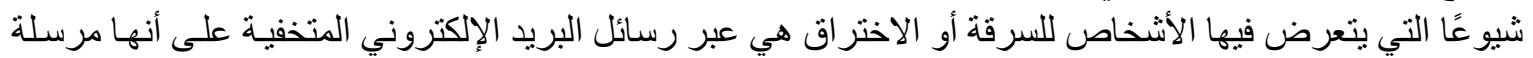
من شخص تثق بها.

\section{(Always up-to-date) التحديثات}

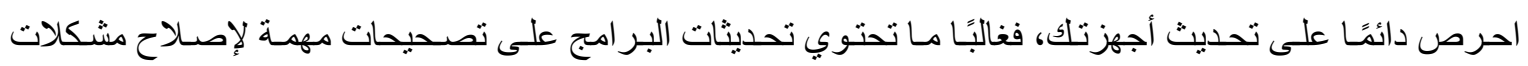

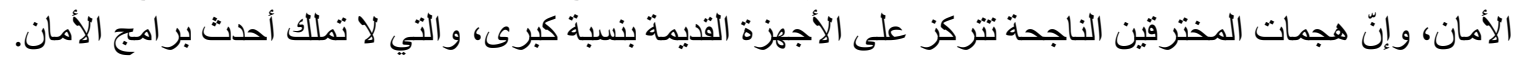




\section{•}

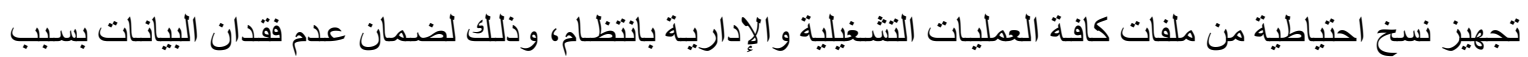
الهجمات من خلال شبكة الإنترنت، و إذا كنت بحاجـة إلى تنظيف جهاز ك (Format) بسبب هجوم إلكتروني سـابق،

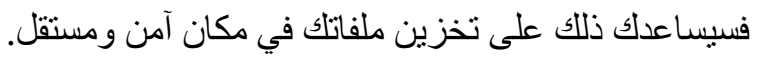

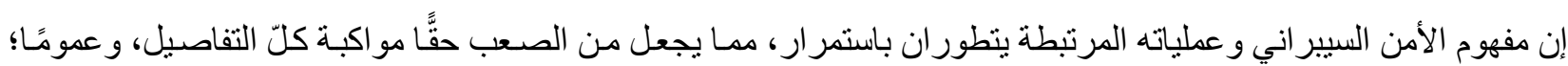

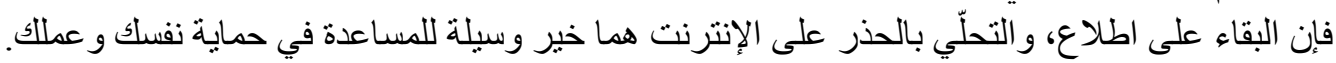

\section{المبحث الثانى: أدوات إدارة وتقييم مخاطر الأمن السيبرانى فى البنوك الأردنية}

\section{مقدمة عن البنوك الأردنية:}

بلغ عدد البنوك في الأردن حتى نهايـة 2018، (24) بنك، منها (13) بنك أردني تجـاري، و(3) بنوك إسـلامية أردنيـة، و(8)

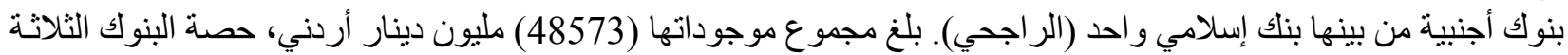

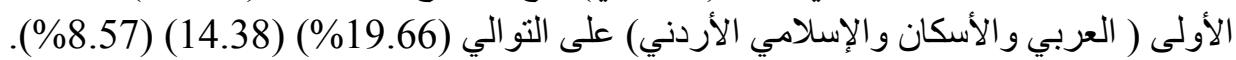

تخضع البنوك الأردنية لقانون البنك المركزي وقانون التجارة الأردني و غير هـا من قو انين تنظم عمليات البنوك، و التي تهدف

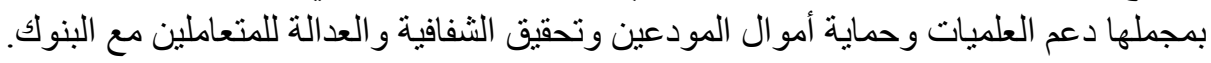

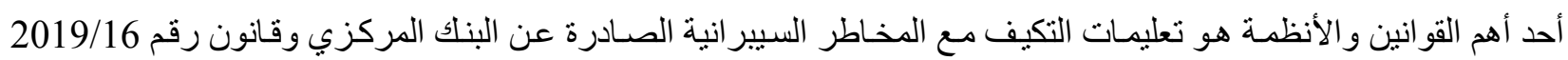

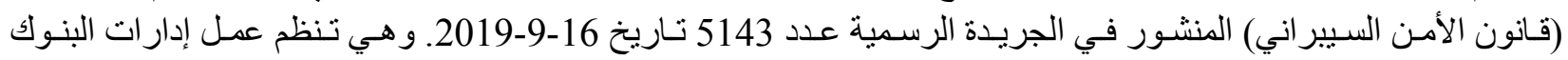

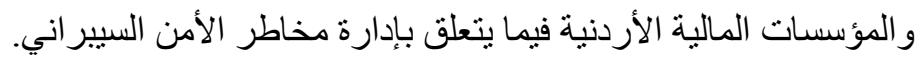

\section{أهمية الأمن السيبرانى في البنوك الأردنية}

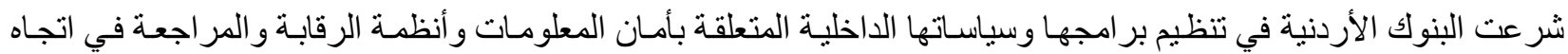

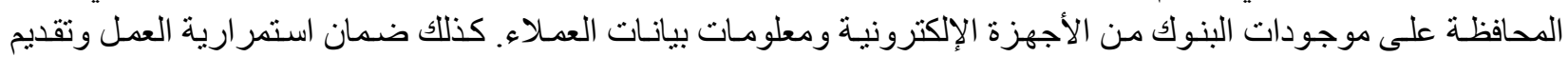
الخدمات على مدار الساعة.

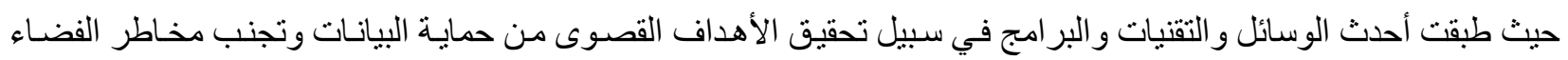

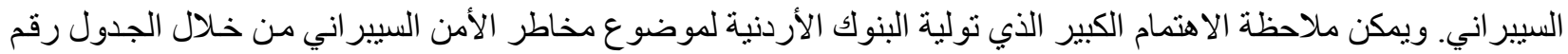

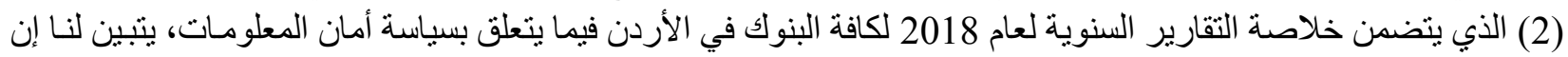

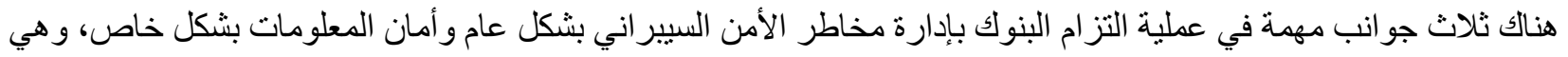

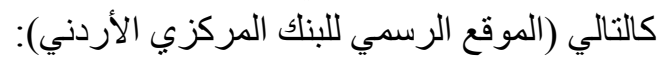

1. وجود سياسة أمان معطومات: بشكل عام فإن جميع البنوك لديها سياسة أمان معلومات يناط بها رسم الخطوط العريضة

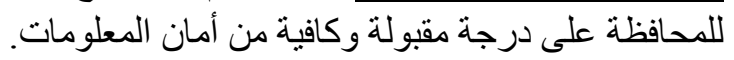

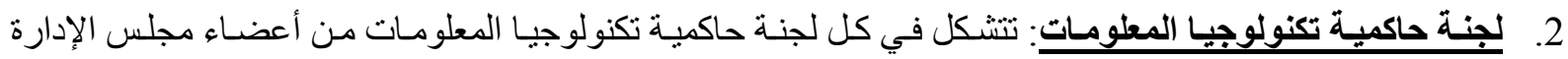

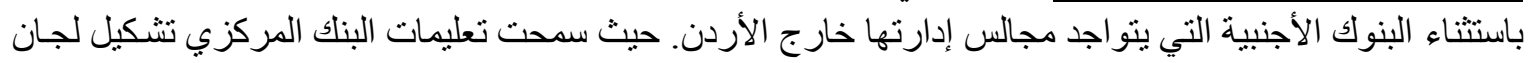

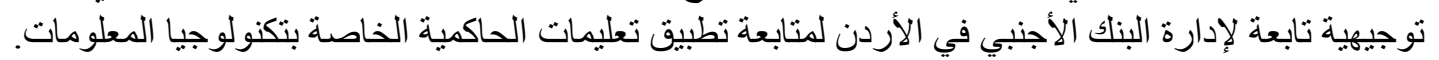

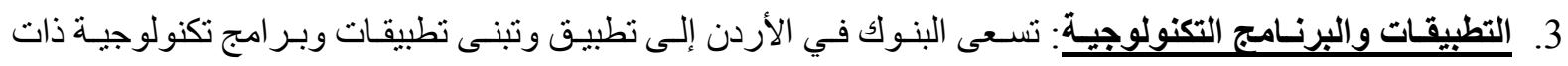

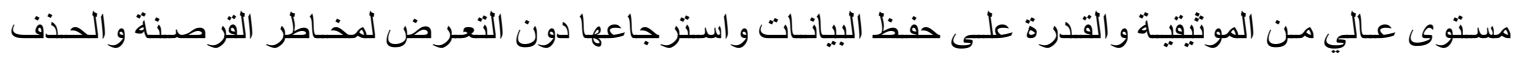

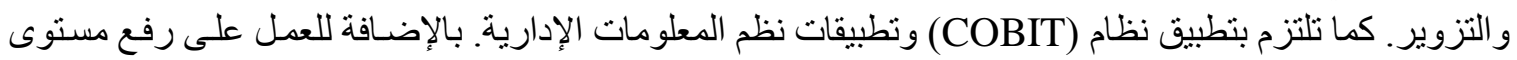

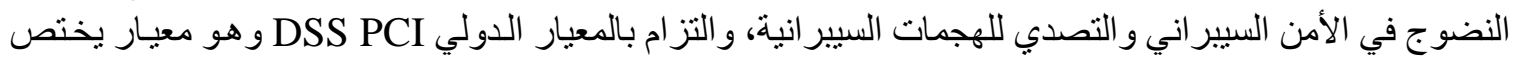
بحماية بيانات حاملي البطاقات عن طريق توفير ضو ابط أمنية خاصة. 


\begin{tabular}{|c|c|c|c|}
\hline & & & جدول رقم (2) \\
\hline |التطبية & 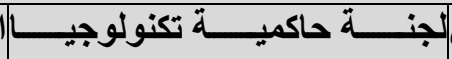 & كجـــود سياســــة أمـــــان|ن & \\
\hline | التكنولوجية & | المعلومات & بعلومات & لبنك \\
\hline$*$ & $*$ & * & لبنك العربي ش م ع \\
\hline$*$ & $*$ & k & |لمؤسيــة العربيـة المصــرفية \\
\hline$*$ & $*$ & $*$ & نأك الأردن \\
\hline$*$ & $*$ & * & بأنك القاهرة عمان \\
\hline$*$ & $*$ & * & بنك المال الأردني \\
\hline$*$ & $*$ & * & البنك التجاري الأردني \\
\hline$*$ & $*$ & & البنك الأردني الكويتي \\
\hline & $*$ & * & البنك الأهلي الأردني \\
\hline$*$ & $*$ & * & بنك الإسكان للتجارة و التمويل|* \\
\hline$*$ & $*$ & & بنك الاستثمار العربي الأردني \\
\hline$*$ & $*$ & * & البنك الاستثماري \\
\hline & $*$ & $*$ & ·: بلك سوسيته جنر ال / الأردن \\
\hline$*$ & $*$ & * & بنك الاتحاد \\
\hline$*$ & $*$ & * & ستاندرد تشارنرد \\
\hline & $*$ & & العربـي لـ العقــاري المصـــري \\
\hline$*$ & $*$ & * & سيتي بنلك إن ـ إيه \\
\hline$*$ & & & مصرف الر افدين \\
\hline$*$ & & & بينك الكويت الوطني \\
\hline$*$ & & * & بنك لبنان و المهجر \\
\hline$*$ & $*$ & * & بنأك عوده ش.م.ل \\
\hline$*$ & $*$ & * & |البناك العربي الإسلامي الدولي|م \\
\hline * & $*$ & k & | البنالك الإسلامي الأردني \\
\hline * & $*$ & * & بنك صفوة الإسلامي \\
\hline & & * & مصرف الر اجحي \\
\hline
\end{tabular}

المصدر: الجدول من إعداد الباحث، المصدر: التقارير السنوية لعام 2018 لكافة البنوك الأردنية

إدارة مخاطر الأمن السييرانى فى البنوك الأردنية:

تهدف البنوك الأردنيـة من إدارة مخاطر الأمن السيبر اني إلى تحقيق الحد الأدنى من المتطلبـات الأساسية للأمن السيبر اني

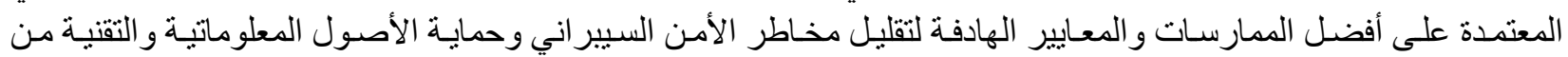

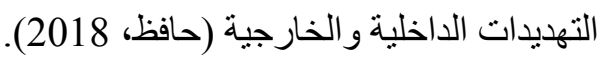

$$
\begin{aligned}
& \text { ترتكز سياسات إدارة المخاطر على ( الثولي، 2018): }
\end{aligned}
$$

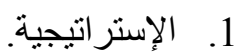

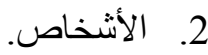

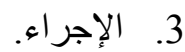

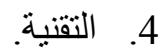




\section{وضع السياسات والإجراءات الخاصة بالأمن السيبرانى:}

1. تحديد سياسات و إجر اءات الأمن السيبر اني، وضو ابط ومنطلبات ذللك، وتوثيقها و اعتمادها من مجلس الإدارة.

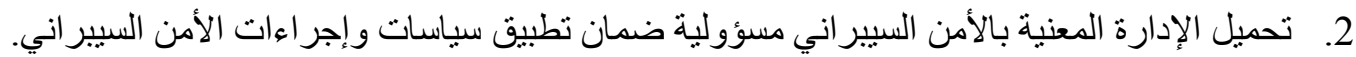

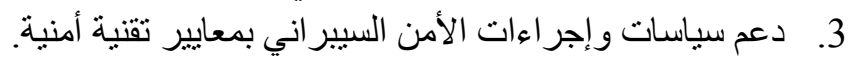

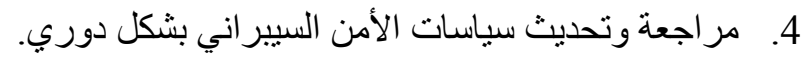

الإجراءات المتبعة من قبل البنوك الأردنية لإدارة مخاطر الأمن السيبراني

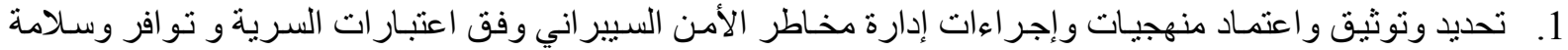
الأصول المعلوماتية والتقنية.

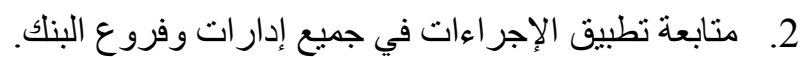

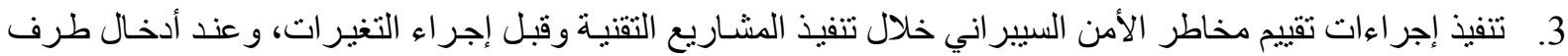

خارجي، و عند أطلاق خدمات جديدة.

4. مر اجعة منهجية و إجراءات إدارة المخاطر السيير انية بشكل دوري وتحديثها وتوثيق التغير ات وفق جدول زمني.

النتائج

في نهاية هذه البحث يمكن الوصول للنتائج التالية:

1. ت تلنزم البنوك الأردنية بالسياسات الخاصة بأمان المعلومات وسياسة الأمن السيبر اني.

2. ت نطبيق ومتابعة جميع التعليمات الصادرة من البنك المركزي الأردني فيما يتعلق بالأمن السيبير اني.

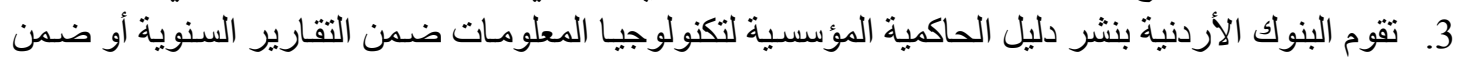

تقارير خاصة على مو اقعها.

التوصيات

بناء على النتائج السابقة التي تم التوصل إليها يمكن صياغة التوصيات التالية: 1- توضيح السياسات المتبعة بخصوص الأمن السيبر اني بشكل أدق.

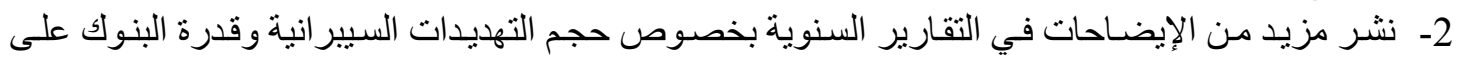

معالجتها.

المراجع العربية

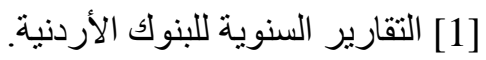

[2] الحجو، زهير، (2011). العولمة التكنلوجية وثار ها على القطاع الهصرفي، بحث مقدم لمؤتمر القطاع المصرفي ورهانات المستقبل، مركز الثمال للار اسات.

[3] الحميد، محمد دباس، نينو، ماركو إبر اهيم، (2007). حماية أنظمة الدعلومات، دار الحامد للنشر.

[4] الجلاب، عاصم، (2014). العولمة المصرفية، بحث مقدم لمؤتمر القطاع المصرفي و العولمة، الطبعة الأولى.

[5] الخمعلي، سليمان، (2013). الامن السبر/ني والاقتصاد السعودي، مكتبة وهبة للنشر و التوزيع.

[6] الرزو، حسن مظفر، (2007). الفضاء الدعلوماتي، مركز دراسات الوحدة العربية.

[7] الثمر اني، عبد الله (2017). الأمن السبراني في القطاع الدصرفي السعودي، مجلة اقتصاديات السوق، العدد 4، المجلد2.

[8] الثولي، اياس، (2018). حماية الدعلومات الدصرفبة، الو اقع و التطلعات، مكتبة بشرى للتوزيع، الطبعة الثانية.

[9] العمر اوي، هلال، (2016). مفاهيم حول الأمن السبراني، دار إثبيلية الحديثة للنشر ، الطبعة الأولى.

[10] حازم، محمد، (2010). الأمن السبراني التحدي الجديب للقطاع المالي، مكتبة الناشر للتوزيع، الطبعة الثانية. 


$$
\begin{aligned}
& \text { [11] حافظ، عبد الله، (2018). امن المعلومات في القطاع المصرفي، مكتبة الرشد للتوزيع، الطبعة الأولى. } \\
& \text { [12] داود، حسن طاهر، (1425). أمن شبكات المعلومات ، معهد الإدارة العامة. } \\
& \text { [13] عبد الباري، سليمان، (2012) ، الأمن السبر/ني، مكتبة البركة للنشر والتوزيع. } \\
& \text { [14] فاضل، حفيظ (2014) ، الامن السبراني وتحديات العولمة، الرياض للنشر و التوزيع، الطبعة الأولى. } \\
& \text { [15] موقع البنك المركزي الأردني. } \\
& \text { المراجع الالجنبية }
\end{aligned}
$$

[1] Kostopoulos, G. (2013). Cyberspace and cybersecurity. New York, USA: CRC Press. 